\title{
Application of UHPLC and GC/MS for Detection of Hidden Drugs in Traditional Hand-Made Herbal Slimming Products
}

\author{
Tayebeh Tahamtan ${ }^{1}$, Maryam Akhgari ${ }^{2,{ }^{*}}$, Zahra Mousavi ${ }^{1}$ and Alireza Jahanbakhsh ${ }^{2}$ \\ ${ }^{1}$ Department of Toxicology and Pharmacology, Faculty of Pharmacy, Pharmaceutical Sciences Branch, Islamic Azad University (IAUPS), Tehran, Iran \\ ${ }^{2}$ Legal Medicine Research Center, Legal Medicine Organization, Tehran, Iran \\ "Corresponding author: Legal Medicine Research Center, Legal Medicine Organization, Tehran, Iran. Email: akhgari1349@yahoo.com
}

Received 2018 August 07; Revised 2018 November 12; Accepted 2018 December 23.

\begin{abstract}
Background: Obesity is one of the health issues all over the world. Patients always demand convenient and fast methods for weight reduction. Hand-made herbal drugs are advertised by herbal practitioners to gain this goal. Unscrupulous manufacturers produce herbal products that are adulterated with hidden legal or illegal drugs to lose weight in a shorter period of time.

Objectives: The main purpose of the present study was to analyze hand-made herbal slimming drugs to detect undeclared active pharmaceutical ingredients.

Methods: Forty hand-made herbal products sold as weight loss aid were prepared from 270 herb shops in Gilan province, Iran, in a six-month period. All samples were analyzed using UHPLC and GC/MS instrumentations.

Results: The results showed that $25 \%$ of collected herbal preparations contained caffeine. Moreover, an unlabeled herbal tablet contained metformin.

Conclusions: Herbal slimming products in Gilan province were not adulterated as much as herbal drugs collected from other provinces in Iran. However, adulteration practices may endanger the health or safety of consumers.
\end{abstract}

Keywords: Hand-Made Herbal Drugs, Slimming Products, Adulteration Practice, Analytical Toxicology

\section{Background}

Obesity is defined as an unnatural and harmful accumulation of fat in the body (1). At least 2.8 million people die due to obesity and overweight each year in the world (1). There are different methods for losing weight, including a reduction in calorie intake, increase daily physical activity, and behavioral changes. However, due to industrialized life, these methods cannot be practiced. Obese subjects always seek for a convenient and rapid method to get rid of their problem (2-4). Herbal preparations had gained popularity and dramatic increment of use due to low cost and easy accessibility without the need for the prescription $(5,6)$. However, it is impossible to lose weight in a short period of time with herbal drugs. For this reason, manufacturers of herbal products adulterate herbal supplements with hidden active pharmaceutical ingredients (APIs) for getting an anti-obesity response in a shorter period of time (6). Adulteration practice is defined as replacing the original herbal drugs partially or totally with other drugs or substances (7). Adulteration of herbal drugs with hidden APIs is becoming an uncontrolled problem in many countries. Different herbal-based pharmaceutical preparations are commercially available for consumers, not always aware of the health risks (8). Many patients turn their therapy protocol to natural supplements for the promotion of wellbeing, lose weight, boosting the immune system, and disease prevention as a safer and natural substitute for conventional drugs (9-12). The vast majority of studies had been performed in many countries to detect adulteration of herbal drugs. Yun et al., developed a rapid method for the simultaneous detection of 25 illegal weight loss compounds in adulterated slimming food supplements (2). Sibutramine, sildenafil, fluoxetine, phenolphthalein, and lorcaserin were detected in herbal weight loss supplements in previous studies $(13,14)$. Evidence from Brazil confirms the presence of sibutramine, phenolphthalein, amfepramone, and fenproporex in dietary weight loss supplements (15). Wang et al. detected sibutramine analogues in herbal weight-reducing drugs (16). Dastjerdi et al., in their survey on herbal weight loss drugs in Kermanshah province, Iran, found that herbal slimming drugs were laced with licit and illicit drugs (6). At the moment, there are no established analytical protocols for the safety establishment of herbal products pro- 
duced and distributed in herb shops in Iran. Also, herbal medicines are not routinely regulated by the health system as for conventional drugs.

We should say that evidence supporting the component analysis of herbal weight loss drugs and their adulteration with APIs are not at satisfactory levels in all provinces in Iran.

\section{Objectives}

This study aimed to analyze herbal drugs used as weight-reducing aid in Gilan province, Iran.

\section{Methods}

\subsection{Sample Collection}

According to the business and occupations data bank, Iran, there are 270 herb shops in 16 cities in Gilan province, Iran. The current study was carried out on 40 allegedly natural hand-made herbal slimming drugs in the period August 2017 till February 2018. The addresses of herb shops in Gilan province, Iran were gathered from electronic databases. It should be noted that herb shops were not equally distributed between 16 cities in Gilan province, and none of the herb shops was registered with the Iran Food and Drug Administration (IFDA). Simple random sampling was used, and $10 \%$ of shops in each city were selected for sample collection. Samples were divided into four major subgroups; tablets, capsules, powders, and powders (as tea bags).

\subsection{Chemicals}

All organic solvents and reagents such as acetonitrile, chloroform, methanol, phosphoric acid, potassium dihydrogen phosphate $\left(\mathrm{KH}_{2} \mathrm{PO}_{4}\right)$, hydrochloric acid (37\%), boric acid, and sodium hydroxide were of analytical reagent grade and high purity and were supplied by Merck Chemical Co. (Darmstadt, Germany). Water for chromatography was used to prepare solid samples. Buffers, mobile phase for ultra-high-performance liquid chromatography (UHPLC) system, and eluents were prepared with water for chromatography (Merck Millipore). Helium gas (99.99\% purity) was supplied by Roham Co. (Tehran, Iran).

\subsection{Methods}

\subsubsection{Sample Preparation and Extraction Procedures}

Tablets were crushed to a fine powder using a mortar and pestle. Bags of herbal teas were opened, and the contents were homogenized. Similarly, the contents of gelatin capsules were emptied and homogenized, while soft gel capsules were squeezed, and the content of capsules was gathered in a tube. Accordingly, sampling was done from herbal distillates, powders, jellies, and oils. Liquid dosage forms were analyzed without dilution.

Extraction of active pharmaceutical ingredients was performed by a simple procedure, dispersive liquid-liquid microextraction (DLLME), exploiting organic solvents as extractants. To make the concentration of $1 \mathrm{mg} / \mathrm{mL}$ of each sample, $2 \mathrm{mg}$ (0.002 $\mathrm{g}$ ) of prepared samples were mixed with $2 \mathrm{~mL}$ of $0.1 \mathrm{M}$ borate buffer $(\mathrm{pH}=9.2)$. Basification of samples ( $\mathrm{pH}=12$ ) was performed using $10 \%$ of aqueous $\mathrm{NaOH}$ for the efficient extraction of drugs with basic chemical structures. Adjustment of $\mathrm{pH}$ of the experiment medium to $\mathrm{pH}=2$ and $\mathrm{pH}=9$ was necessary for adequate extraction of drugs with acidic structure and amphoteric drugs, respectively. A prepared mixture of disperser and extractant solvents consisting of $2.5 \mathrm{~mL}$ of methanol and $30 \mu \mathrm{L}$ chloroform was pushed to one $\mathrm{mL}$ of samples at different $\mathrm{pH}$. The mixture was ultrasonicated for $5 \mathrm{~min}$ and centrifuged. The chloroform layer was collected from the bottom of the conical tube and dried under a gentle stream of nitrogen gas. Residues were reconstituted in $30 \mu \mathrm{L}$ methanol and analyzed using ultrahigh-performance liquid chromatography (UHPLC) and gas chromatography/mass spectrometry (GC/MS) instrumentations. All steps of extraction procedures were prevalidated in the laboratory. Limit of detection (LOD), limit of quantitation (LOQ), selectivity, linearity, recovery, coefficient of variation (CV\%), accuracy, and precision were evaluated for drugs of forensic interest such as amphetaminetype stimulants, narcotic analgesics, ethanol, methadone, tramadol, benzodiazepines, barbiturates, and tricyclic antidepressants and also caffeine and metformin as detected adulterants $(6,17,18)$.

\subsubsection{Instrumentations and Conditions}

Ultra-high-performance liquid chromatography (UHPLC) was performed using the KNAUER photodiode array (PDA) detector and autosampler (PDA-1,6 channels). Eurospher II 100-3 C18 $(100 \mathrm{~mm} \times 3 \mathrm{~mm})$ column was used for suspected analyte separation. Two pumps with a degasser module, mixing chamber and high-pressure gradient mode (100 mL/min), and 750 bar were used. Loop, tubing and syringe volumes of autosampler AS- 1 were set at $10,15,250 \mu \mathrm{L}$, respectively. The mobile phase consisted of phosphate buffer $(\mathrm{pH}=2.32)$ and acetonitrile (63:37).

In the case of GC/MS analysis, analyte separation was performed on a silica capillary column (HP5-MS), crosslinked 5\% methyl phenyl silicone, 30 m length $\times 0.25 \mathrm{~mm}$ ID $\times 0.25 \mu \mathrm{m}$ film thickness; Agilent model 7890 A gas chromatograph (Agilent Technologies, Sdn Bhd, Selangor, Malaysia). The capillary column was connected to a mass analyzer (MS 5975 C) (Agilent Technologies) operated by 
electron impact (70ev) in full scan mode (scan range 50 $550 \mathrm{~m} / \mathrm{z}$ ). The oven temperature was programmed at $60^{\circ} \mathrm{C}$ for one minute and increased to the final temperature, $280^{\circ} \mathrm{C}$ at $2^{\circ} \mathrm{C} / \mathrm{min}$. Helium gas was used as a carrier gas with a flow rate of $1.5 \mathrm{~mL} / \mathrm{min}$. The injection port and interface temperatures were 250 and $280^{\circ} \mathrm{C}$, respectively. NIST, Wiley, and MPW 2011 libraries were used for the qualitative determination of hidden pharmacologic ingredients.

\section{Results}

To detect active pharmaceutical ingredients in herbal weight loss drugs, hand-made herbal slimming products were analyzed using UHPLC and GC/MS instrumentations. Results of the toxicological analysis showed that nine samples (22.5\%) contained caffeine, and one sample (2.5\%) contained metformin. Chromatograms and mass spectra for caffeine and metformin obtained from GC/MS analysis are shown in Figures 1-4. Dosage forms, brand names, active ingredients, and the number of active ingredients in different dosage forms are shown in Table 1. Probable sources of natural organic compounds that were detected in herbal drugs are demonstrated in Table 2. Figure 5 indicates one pack of unlabeled herbal-based slimming drugs containing caffeine. LOD and LOQ for caffeine and metformin using GC/MS instrumentation are shown in Table 3.

\section{Discussion}

According to the results of the present study, herbal weight-reducing drugs that are sold in herb shops in Gilan province, Iran are less adulterated with APIs in comparison to herbal drugs analyzed in other provinces in Iran $(6,17-20)$. Dastjerdi et al. confirmed that $72 \%$ of herbal weight loss supplements in Kermanshah province, Iran were adulterated with tramadol, caffeine, methadone, venlafaxine, rizatriptan, and fluoxetine (6). Most undeclared ingredients, which were illegally added to eight brands of herbal weight loss supplements with Chinese and Southeast Asian countries origin included sibutramine, phenolphthalein, bumetanide, phenytoin, rimonabant, caffeine, pseudoephedrine, theobromine, and amfepramone using GC-MS assay (17). The difference may be due to several factors, accessibility to drugs are not the same in disparate parts of the country. Also, the desire for herbal drugs and demand for supplementary therapy are different in distinct parts of one country at different time points. However, some traditional herbal formulations were adulterated with drugs such as caffeine and metformin. A considerable body of evidence has been gathered regarding herbal drug adulteration. Ching et al., in their study, stated that weight-reducing drugs were the most frequently reported indication for the use of adulterated products. They showed that although sibutramine was withdrawn from the market in Hong Kong, the ban on the use of this drug did not eradicate its application in weight loss supplements (11). In contrast to the results of the present study Shekari et al. detected sibutramine, ampheprone, caffeine, and phenolphthalein in slimming pills produced in China, Taiwan, and southeast countries (21). The discrepancy may be due to the drug sources. All of the herbal samples in the present study were prepared from local herb shops and produced in Iran. Phenolphthalein, sibutramine, caffeine, and phendimetrazine were detected in herbal weight loss drugs with Chinese and Southeast Asian sources in previous studies (21). In addition to herbal weight loss supplements, other herbal preparations were adulterated with hidden active pharmaceutical ingredients. Foroughi and co-workers, in their study on herbal drugs advertised as opioid replacement therapy, indicated that more than $96 \%$ of these kinds of drugs were adulterated with diphenoxylate, tramadol, fluoxetine, and sertraline (18). Eighty herbal sexual enhancer pharmaceutical preparations were analyzed in Bushehr city, Iran. Results showed that more than $86 \%$ of herbal sexual enhancer drugs were adulterated with sildenafil as undeclared API. Other hidden drugs were tramadol and diazepam that were detected in combination with sildenafil (19). However, the present research has made a strong case that not all herbal and pharmaceutical products are adulterated with APIs.

Labeling herbal products as "natural products" has led to the rampant use of multi-herb-based products for the control and treatment of a myriad of diseases (22). A survey conducted by the United States Food and Drug Administration showed that in 2007 - 2014 about $40 \%$ of adulterated dietary supplements were advertised as weight loss products (23).

The aim of adding APIs to herbal weight loss drugs is based on the pharmacologic properties of drugs. In the literature review, this study is the first to show metformin detection in herbal slimming supplements. Metformin has been used as anti-diabetic drug for over 60 years. However, the mechanism of its anti-obesity effect is not well understood. Some studies suggested that metformin decreases gluconeogenesis and increases glycolysis in the intestinal epithelial cells (24). Methylxanthines such as caffeine are added secretly to herbal products used as weight loss aid, athletics performance enhancers, and energetics due to their stimulating and thermogenic effects (25). Caffeine exerts its lipolysis activity through the induction of fatty acid beta-oxidation (26). Unfortunately, the amount of undeclared APIs in adulterated drugs is obscure for consumers. Moreover, many patients do not have sufficient 


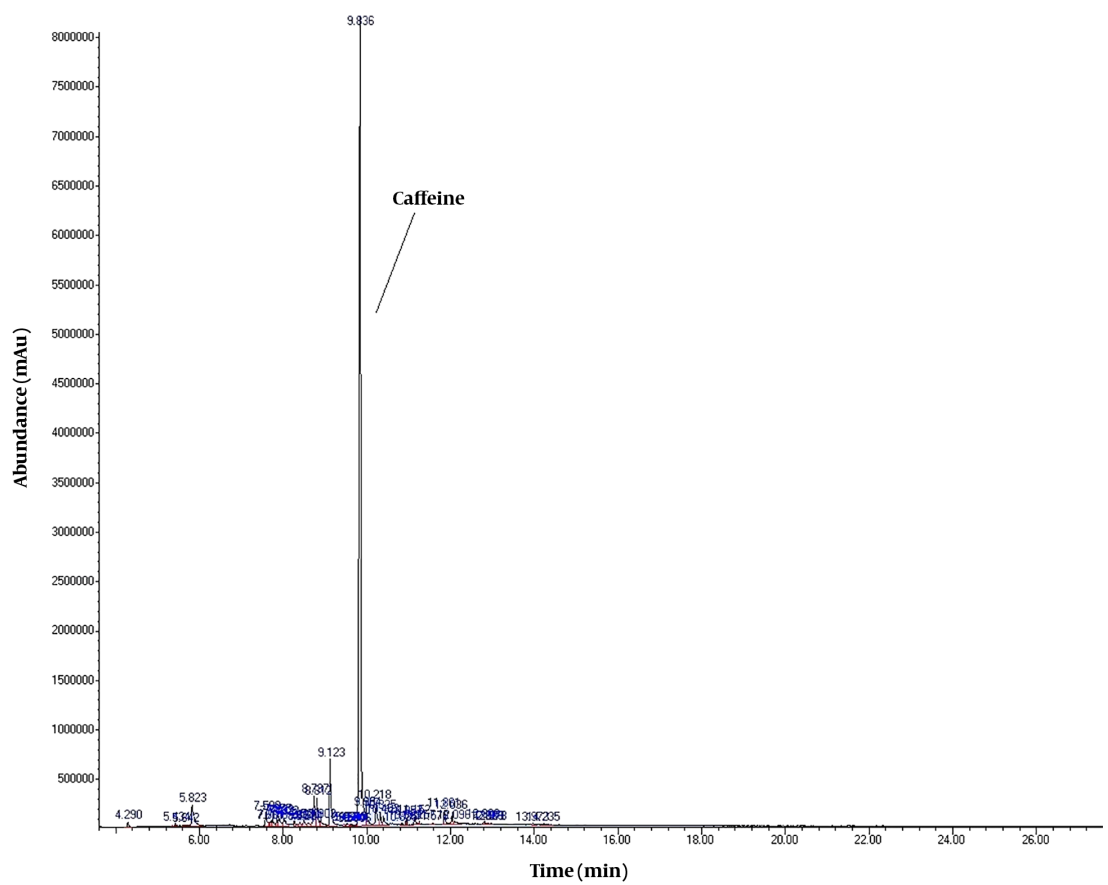

Figure 1. Chromatogram of caffeine acquired using GC/MS instrumentation.

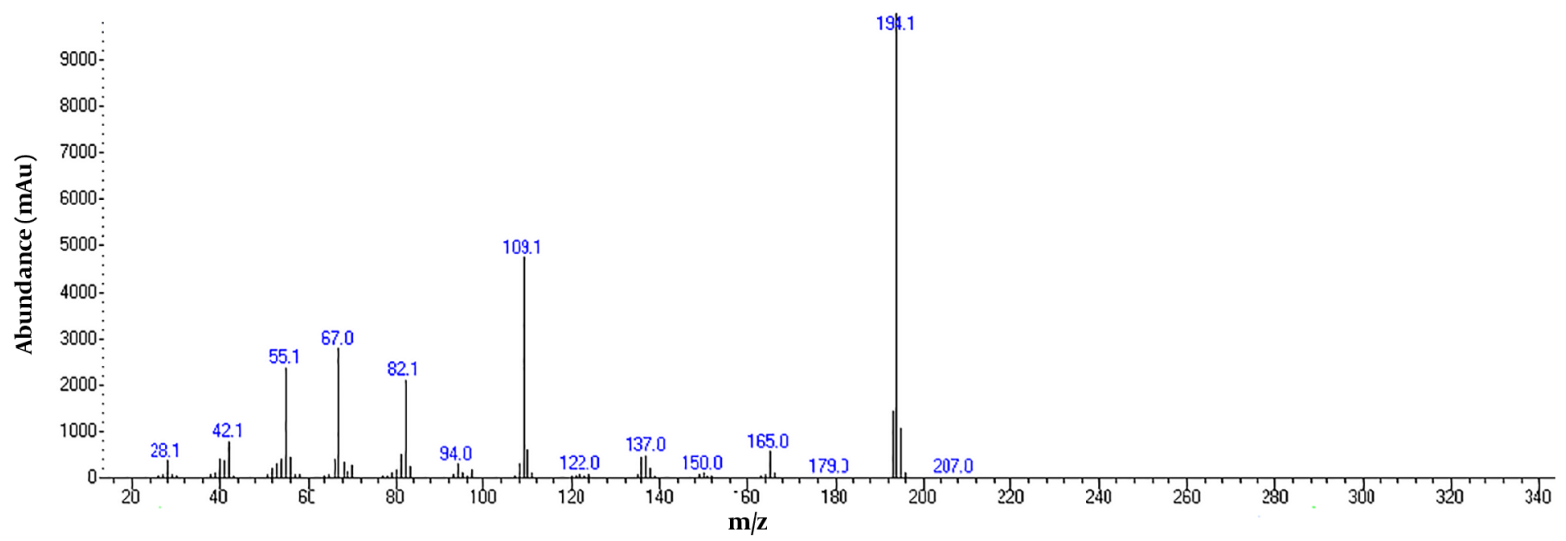

Figure 2. Mass Spectra of caffeine acquired using GC/MS instrumentation.

information about the risks and side effects of laced natural products. Self-administration of adulterated and deceptive herbal drugs and other natural remedies supplied by internet vendors, retail stores, and unauthorized herbal practitioners could result in health consequences not easily treated by conventional drug therapy $(5,27)$.

Medicinal plants can be collected from different parts of plants, including stem, bark, leaf, flowers, roots, as well as the whole plant body (26). Component analysis of herbal drugs in the present study showed that many products contained natural organic compounds. Many of these natural compounds have protective and diseasepreventing effects (26). They exert their anti-obesity activity via improvement in lipid metabolism, insulin sensitivity, decrease in fat mass, food intake, and lipid accumulation in adipose tissues, thereby lowering body weight (26). 


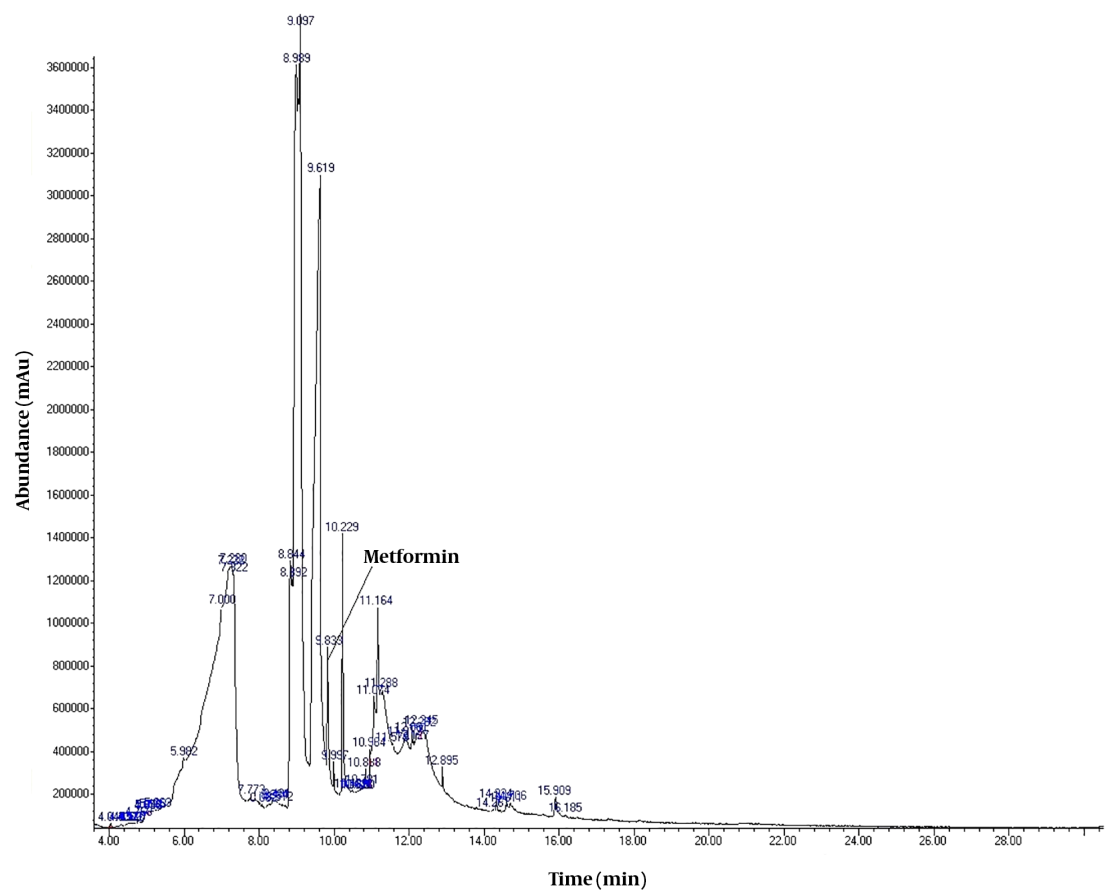

Figure 3. Chromatogram of metformin acquired using GC/MS instrumentation.

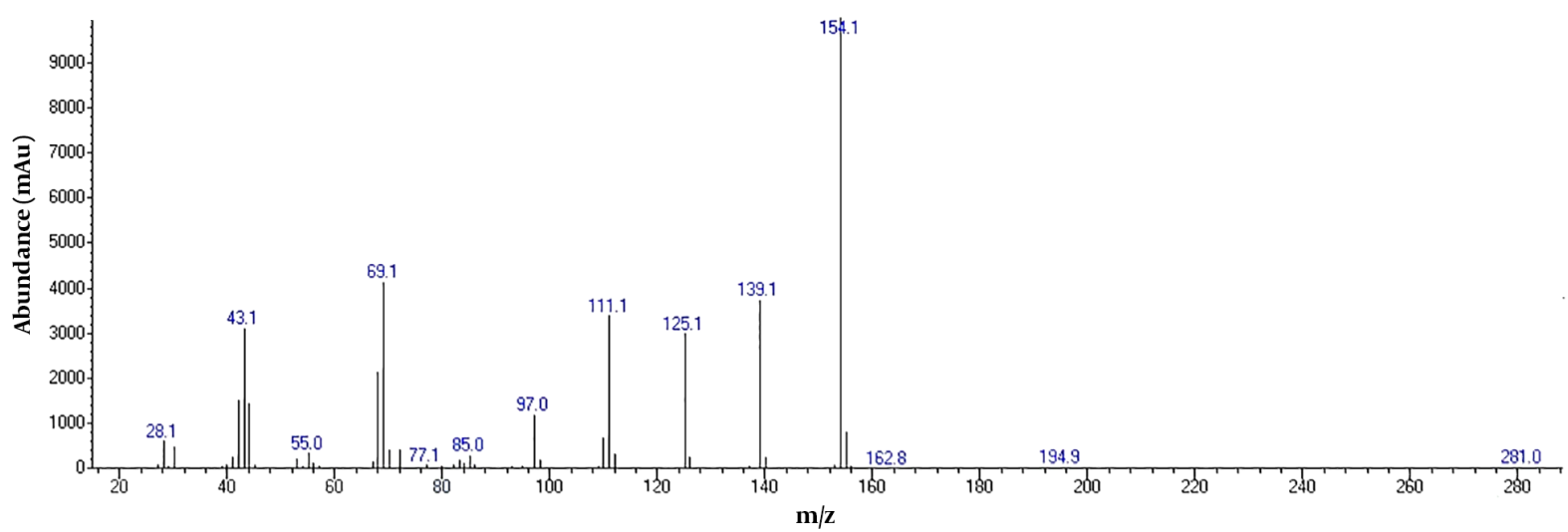

Figure 4. Mass Spectra of metformin acquired using GC/MS instrumentation.

\subsection{Recommendations}

We recommend further studies using a larger sample size, including handmade, factory-made, and natural pharmaceutical products produced in different countries to build a well-managed data store for adulterated herbal and natural supplements.

\subsection{Conclusion}

Adulterated herbal products have many side effects that overweigh their beneficial effects. Increased selfmedication practice and poor patients' knowledge about the composition of drugs necessitates information provision to improve public health. 


\begin{tabular}{|c|c|c|}
\hline Brand Name & Dosage Form & Detected Ingredients \\
\hline Slim quick & Orange tablets & Dillapiole, elemicin, myristicin, cineole, apiol, caffeine \\
\hline Lemon extract & Soft gelatin capsule & Terpinen, pinene, camphene \\
\hline Fitana & Dark green tablets & Myristicin, elemicin, apiole, caffeine \\
\hline Carvil & Dark green tablets & Myristicin, elemicin, apiole, selinene, sedanolide, senkyunolide, caffeine \\
\hline Cumin extract & Dark green tablets & Sabinene, camphene, limonene, menthadiene, carvacrol, $\alpha$-tocopherol, caffeine \\
\hline Slimmax & White-pink hard gelatin capsules & Cumminaldehyde, $\alpha$-selinene, senkyunolide, caffeine \\
\hline Unlabeled herbal tea & Tea bags & Cumminaldehyde, caffeine \\
\hline Slim pharm & White-pink hard gelatin capsules & Caffeine \\
\hline Unlabeled herbal powder & Green powder & Caffeine \\
\hline Unlabeled herbal tablets & Green tablets & Metformin \\
\hline Unlabeled herbal powder & powder & Sedanolide, senkyunlide, $\alpha$-selinene, caffeine, thymol, anethol, apiole \\
\hline
\end{tabular}

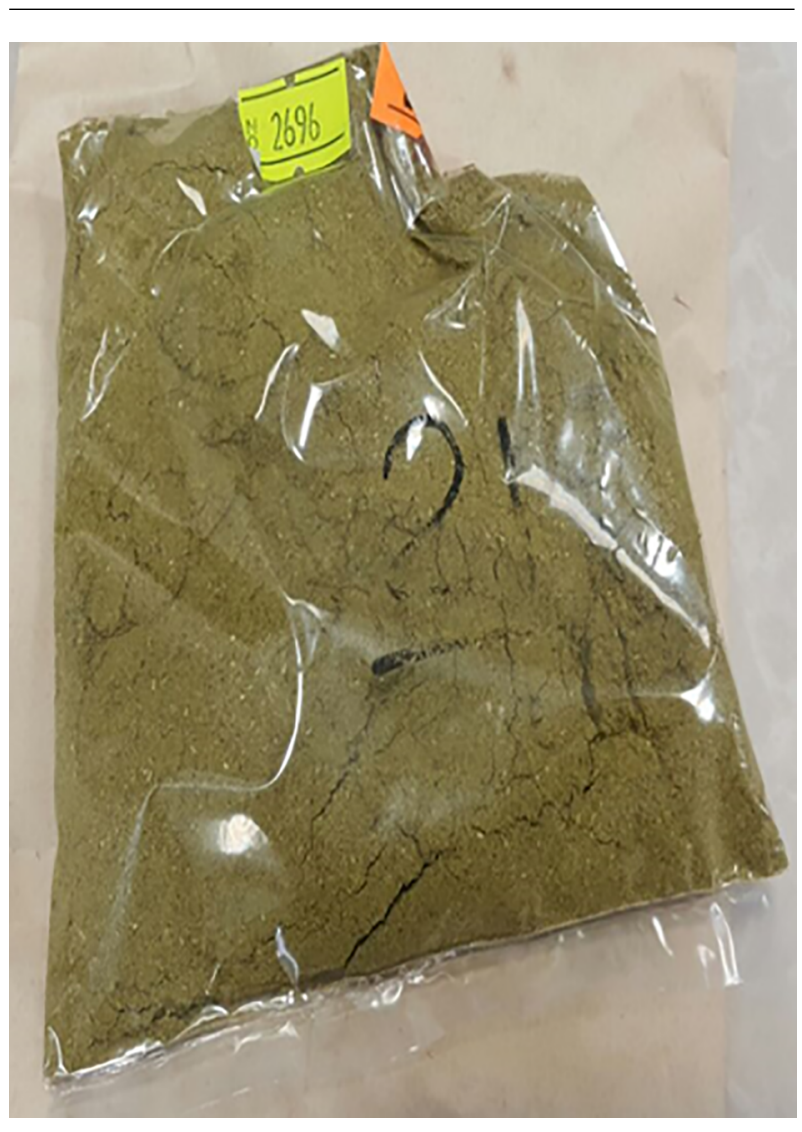

Figure 5. One pack of unlabeled herbal-based slimming drugs, containing caffeine.

\section{Footnotes}

Authors' Contribution: TT participated in designing the study and data collection. MA participated in designing
Table 2. Probable Sources of Natural Organic Compounds That Were Detected in Hand-made Herbal Slimming Drugs in Gilan Province, Iran (Reference: WIKIPEDIA, The Free Encyclopedia)

\begin{tabular}{|c|c|}
\hline Detected Ingredients & Probable Sources of Detected Ingredients \\
\hline Myristicin, Elemicin & $\begin{array}{l}\text { Natural organic compounds in nutmeg, parsley } \\
\text { and dill }\end{array}$ \\
\hline Cineole & $\begin{array}{l}\text { Flavoring agent and the main constituent of } \\
\text { eucalyptus oil }\end{array}$ \\
\hline Apiole & An ingredient found in parsley \\
\hline$\alpha$-Terpinene & $\begin{array}{l}\text { Natural organic compound isolated from } \\
\text { cardamom and marjoram oils }\end{array}$ \\
\hline$\alpha$-Pinene & $\begin{array}{l}\text { One of the components of cumin, humulus, pinus, } \\
\text { clausena and cannabis plants }\end{array}$ \\
\hline Camphene & $\begin{array}{l}\text { It is a constituent of camphor oil, citronella oil, } \\
\text { ginger oil and valerian }\end{array}$ \\
\hline$\alpha$-Selinene & $\begin{array}{l}\text { It is one of the principal components of the celery } \\
\text { seed oil }\end{array}$ \\
\hline Sedanolide & It is one of the constituents of fresh celery oil \\
\hline Sabinene & $\begin{array}{l}\text { It is one of the major constituents of carrot seed oil } \\
\text { and also }\end{array}$ \\
\hline Limonene & $\begin{array}{l}\text { It is one of the major components of citrus fruit } \\
\text { peel }\end{array}$ \\
\hline Carvacrol & $\begin{array}{l}\text { A compound with pungent characteristic and } \\
\text { warm odor of oregano }\end{array}$ \\
\hline Cuminaldehyde & It is an essential oil of eucalyptus, myrrh and cassia \\
\hline Anethol & $\begin{array}{l}\text { An aromatic compound that contributes a large } \\
\text { component of the odor and flavor of anise and } \\
\text { fennel }\end{array}$ \\
\hline
\end{tabular}

the study, interpreting the data, performing toxicological analysis, and drafting the manuscript. MA participated in coordinating and helped draft the manuscript. ZM supervised and participated in drafting the manuscript. AJ participated in designing the study. All authors read and approved the final manuscript. 
Table 3. Limit of Detection (LOD) and Limit of Quantitation (LOQ) for Caffeine and Metformin Acquired Using GC/MS Instrumentation

\begin{tabular}{lcc}
\hline Drug Name & LOD $(\mathbf{n g} / \mathbf{L})$ & LOQ $(\mathbf{n g} / \mathbf{L})$ \\
\hline Caffeine & 1.23 & 4.3 \\
Metformin & 0.35 & 1.16 \\
\hline
\end{tabular}

Conflict of Interests: Authors have no financial interests related to the materials used in the manuscript.

Funding/Support: None.

\section{References}

1. World Health Organization (WHO). Obesity. 2020. Available from: http://www.who.int/topics/obesity/en/.

2. Yun J, Choi J, Jo CH, Kwon K. Detection of Synthetic Anti-Obesity Drugs, Designer Analogues and Weight- Loss Ingredients as Adulterants in Slimming Foods from 2015 to 2017. Journal of Chromatography and Separation Techniques. 2018;9(1). doi:10.4172/2157-7064.1000396.

3. Erdogan Z, Kurtuncu M. Use of Dietary Supplements for Weight Loss in Obese Patients in Zonguldak, Turkey. African Journal of Traditional, Complementary and Alternative medicines. 2018;15(1):59-65. doi: 10.21010/ajtcam.v15i1.6.

4. Payab M, Hasani-Ranjbar S, Aletaha A, Ghasemi N, Qorbani M, Atlasi $\mathrm{R}$, et al. Efficacy, safety, and mechanisms of herbal medicines used in the treatment of obesity: A protocol for systematic review. Medicine (Baltimore). 2018;97(1). e8825. doi: 10.1097/MD.0000000000008825. [PubMed: 29505506]. [PubMed Central: PMC5943094].

5. Bayisa B, Tatiparthi R, Mulisa E. Use of Herbal Medicine Among Pregnant Women on Antenatal Care at Nekemte Hospital, Western Ethiopia. Jundishapur Journal of Natural Pharmaceutical Products. 2014;9(4). doi: 10.17795/jjnpp-17368.

6. Dastjerdi AG, Akhgari M, Kamali A, Mousavi Z. Principal component analysis of synthetic adulterants in herbal supplements advertised as weight loss drugs. Complementary Therapies in Clinical Practice. 2018;31:236-41. doi:10.1016/j.ctcp.2018.03.007.

7. Khare B, Mishra MK, Kesharwani L. Screening of adulterants in herbal formulations for forensic considerations. Journal of Pharmacognosy and Phytochemistry. 2018;7(2):532-6.

8. Pascali JP, Fais P, Vaiano F, Bertol E. Application of HRAM screening and LC-MS/MS confirmation of active pharmaceutical ingredient in "natural" herbal supplements. Forensic Science International. 2018;286:e28-31. doi: 10.1016/j.forsciint.2018.03.014.

9. Sattari M, Dilmaghanizadeh M, Hamishehkar H, Mashayekhi S. Selfreported Use and Attitudes Regarding Herbal Medicine Safety During Pregnancy in Iran. Jundishapur Journal of Natural Pharmaceutical Products. 2012;7(2):45-9. doi: 10.5812/jjnpp.3416.

10. Ebrahimi E, Shirali S, Afrisham R. Effect and Mechanism of Herbal Ingredients in Improving Diabetes Mellitus Complications. Jundishapur Journal of Natural Pharmaceutical Products. 2016;12(1). doi: 10.5812/jjnpp.31657.

11. Ching CK, Chen SPL, Lee HHC, Lam YH, Ng SW, Chen ML, et al. Adulteration of proprietary Chinese medicines and health products with undeclared drugs: experience of a tertiary toxicology laboratory in Hong Kong. British Journal of Clinical Pharmacology. 2018;84(1):172-8. doi: 10.1111/bcp.13420.

12. Benatrehina P, Pan L, Naman C, Li J, Kinghorn A. Usage, biological activity, and safety of selected botanical dietary supplements con- sumed in the United States. Journal of Traditional and Complementary Medicine. 2018;8(2):267-77. doi:10.1016/j.jtcme.2018.01.006.

13. Hachem R, Assemat G, Martins N, Balayssac S, Gilard V, Martino R, et al. Proton NMR for detection, identification and quantification of adulterants in 160 herbal food supplements marketed for weight loss. Journal of Pharmaceutical and Biomedical Analysis. 2016;124:34-47. doi: 10.1016/j.jpba.2016.02.022.

14. Kim JW, Kweon SJ, Park SK, Kim JY, Lee JH, Han KM, et al. Isolation and identification of a sibutramine analogue adulterated in slimming dietary supplements. Food Additives and Contaminants: Part A. 2013;30(7):1221-9. doi: 10.1080/19440049.2013.793826.

15. Neves DBDJ, Caldas ED. Determination of caffeine and identification of undeclared substances in dietary supplements and caffeine dietary exposure assessment. Food and Chemical Toxicology. 2017;105:194-202. doi: 10.1016/j.fct.2017.03.063.

16. Wang J, Chen B, Yao S. Analysis of six synthetic adulterants in herbal weight-reducing dietary supplements by LC electrospray ionizationMS. Food Additives and Contaminants: Part A. 2008;25(7):822-30. doi: 10.1080/02652030801946553.

17. Khazan M, Hedayati M, Kobarfard F, Askari S, Azizi F. Identification and Determination of Synthetic Pharmaceuticals as Adulterants in Eight Common Herbal Weight Loss Supplements. Iranian Red Crescent Medical Journal. 2014;16(3). doi: 10.5812/ircmj.15344.

18. Foroughi $\mathrm{MH}$, Akhgari $\mathrm{M}$, Jokar F, Mousavi Z. Identification of undeclared active pharmaceutical ingredients in counterfeit herbal medicines used as opioid substitution therapy. Australian Journal of Forensic Sciences. 2017;49(6):720-9. doi: 10.1080/00450618.2016.1273387.

19. Fard $\mathrm{HH}$, Akhgari M. Analytical perspectives of chemical adulterants in herbal sexual enhancer drugs. J Pharm Pharmacogn Res. 2018;6:4553.

20. Saberi N, Akhgari M, Bahmanabadi L, Bazmi E, Mousavi Z. Determination of synthetic pharmaceutical adulterants in herbal weight gain supplements sold in herb shops, Tehran, Iran. DARU Journal of Pharmaceutical Sciences. 2018;26(2):117-27. doi:10.1007/s40199-018-0216-2.

21. Shekari N, Vosough M, Tabar Heidar K. Chromatographic fingerprinting through chemometric techniques for herbal slimming pills: A way of adulterant identification. Forensic Science International. 2018;286:213-22. doi:10.1016/j.forsciint.2018.03.022.

22. Fakhri S, Mohammadi B, Jalili R, Hajialyani M, Bahrami G. Screening and Confirmation of Different Synthetic Adulterants in Slimming Products. Asian Journal of Pharmaceutical and Clinical Research. 2018;11(2):260. doi: 10.22159/ajpcr.2018.v11i2.22516.

23. Tsarouhas K, Kioukia-Fougia N, Papalexis P, Tsatsakis A, Kouretas D, Bacopoulou F, et al. Use of nutritional supplements contaminated with banned doping substances by recreational adolescent athletes in Athens, Greece. Food and Chemical Toxicology. 2018;115:447-50. doi: 10.1016/j.fct.2018.03.043.

24. Skalicka-Woźniak K, Georgiev MI, Orhan IE. Adulteration of herbal sexual enhancers and slimmers: The wish for better sexual wellbeing and perfect body can be risky. Food and Chemical Toxicology. 2017;108:355-64. doi:10.1016/j.fct.2016.06.018.

25. Gonzalez FJ, Jiang C. A Western diet-induced mouse model reveals a possible mechanism by which metformin decreases obesity. European Journal of Clinical Pharmacology. 2017;73(10):1337-9. doi: 10.1007/s00228-017-2322-3.

26. Ozdemir B, Sahin I, Kapucu H, Celbis O, Karakoc Y, Erdogan S, et al. How safe is the use of herbal weight-loss products sold over the Internet? Human and Experimental Toxicology. 2012;32(1):101-6. doi: $10.1177 / 0960327112436407$.

27. Rao SP. Herbal Approach for the Management of Obesity - A Review. International Journal of Pure \& Applied Bioscience. 2018;6(1):147-58. doi: 10.18782/2320-7051.6169. 